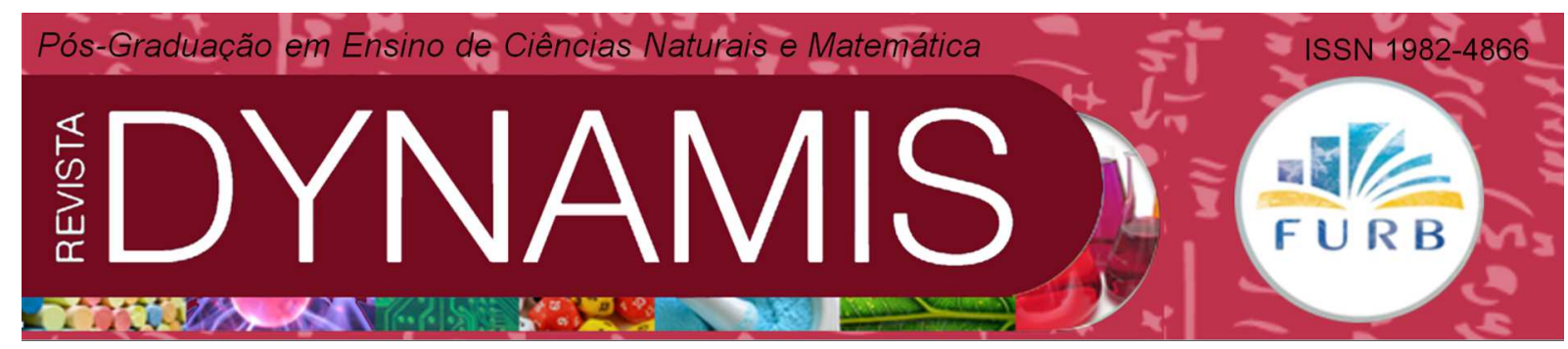

\title{
ANÁLISE PIAGETIANA DO DESENVOLVIMENTO COGNITIVO: EXPERIÊNCIAS COM CRIANÇAS DO ENSINO FUNDAMENTAL
}

Analysis of cognitive development Piaget: experiences of elementary school children

Tatiana Comiotto Menestrina

Wesley Saade

Mayara Reinert Gelamo

Pamela Paola Leonardo 


\title{
Resumo
}

A compreensão do desenvolvimento humano é importante e necessária para o planejamento de como e o que deve ser aplicado no ensino em cada idade. Ao estudar as experiências de Piaget com crianças de idade entre dois e treze anos, nota-se que alguns atingem um estado de conhecimento de dado conceito precocemente, enquanto outros só os adquirem tardiamente. A proposta deste artigo é comparar as conclusões de Piaget com os resultados obtidos através de experimentos práticos realizados com crianças que são avaliados conforme a faixa etária correspondente.

Palavras-chave: : Experiências. Desenvolvimento Cognitivo. Piaget, Educação.

\begin{abstract}
The understanding of human development is important and necessary for planning how and what should be applied in education at every age. By studying the experiences of Piaget with children aged between two and thirteen, note that there are children who reach a state of knowledge of the given concept early, and others only get late. The aim of this paper is to compare the findings of Piaget with the results obtained from practical experiments on children are evaluated according to their corresponding age group.
\end{abstract}

Keywords: Experience. Cognitive Development. Piaget. Education. 


\section{INTRODUÇÃO}

A teoria desenvolvida por Piaget na primeira metade do século XX permite agrupar sujeitos em determinados estágios do desenvolvimento cognitivo, dependendo da idade. Porém, desde a formulação desta teoria, ocorreram fatos e mudanças de comportamentos muito significativos na sociedade. Esse trabalho tem como objetivo comprovar as experiências testadas por Piaget no século passado e relacioná-las com as crianças e seu desenvolvimento na atualidade.

A compreensão do desenvolvimento humano é importante e necessária para o planejamento de como e o que deve ser aplicado como ensino a certa idade. Estudar as características em comum das faixas etárias vem contribuir para o melhor aproveitamento da fase educacional do ser humano, já que existem formas de perceber, entender e agir diante do mundo, próprias de cada faixa etária (SANTANA, 2010).

Jean Piaget (1896 - 1980) foi um epistemólogo suíço, conhecido por seus estudos sobre o desenvolvimento cognitivo. Através de uma minuciosa observação de seus filhos e outras crianças, criou a Teoria Cognitiva, que propõe quatro estágios no desenvolvimento do ser humano: sensório-motor, pré-operatório, operatório concreto e operatório formal.

Ao estudar as experiências de Piaget com crianças de idades entre dois e treze anos, notase que algumas delas atingem um estado de conhecimento de dado conceito precocemente, e outras só o adquirem tardiamente. Isto se deve a diversos fatores, entre os quais é possível citar: a maturação neurofisiológica (o que torna plausível determinado padrão de conhecimento) e o meio, tanto social quanto econômico.

\section{METODOLOGIA}

Este trabalho é fruto de uma pesquisa de campo que foi realizada pelos acadêmicos do curso de Licenciatura em Física da Universidade do Estado de Santa Catarina de março a junho de 2010, na disciplina de Psicologia da Educação.

Os acadêmicos elegeram a faixa etária que iriam aplicar seus estudos e quais as experiências desenvolver, em conformidade com Piaget. Os experimentos realizados referiam-se a: classificação aditiva antecipatória, classificação auditiva visual, classificação multiplicativa, compensação complexa, operação lógica de probabilidade, composição de classe, conceito de número, conservação de quantidades contínuas, conservação de quantidades descontínuas, conservação de superfície, conservação de volume espacial, conservação do comprimento, conservação do volume, constância da forma e constância de grandeza, noção de objeto permanente, correspondência serial, flexibilidade de hastes metálicas, flutuação de corpos, combinação de objetos, multiplicação lógica de classes, noção de espaço, noção dos conceitos de conservação de peso, noções de causalidade, noções de velocidade, pensamento proporcional, combinações de ideias, seriação complexa, seriação simples, compensação simples, ordem linear e transitividade.

As experiências foram filmadas e depois transcritas, conforme os relatos a seguir. Os participantes do estudo, bem como seus responsáveis legais assinaram o Termo de Consenti- 
mento Livre e Esclarecido e para manter em sigilo as identidades das crianças seus nomes sofram substituídos por números, conforme quadro1:

Quadro 1- Crianças, idades, cidades e nível socioeconômico:

\begin{tabular}{|c|c|c|c|}
\hline Criança & Idade & Cidade & Nível socioeconômico \\
\hline $\mathrm{C} 1$ & 9 anos & Joinville & $\mathrm{C}$ \\
\hline $\mathrm{C} 2$ & 5 anos & Joinville & $\mathrm{C}$ \\
\hline $\mathrm{C} 3$ & 2 anos e 2 meses & Joinville & $\mathrm{B}$ \\
\hline $\mathrm{C} 4$ & 2 anos e 9 meses & Joinville & $\mathrm{C}$ \\
\hline $\mathrm{C} 5$ & 12 anos & Joinville & $\mathrm{C}$ \\
\hline C6 & 7 anos & Joinville & $\mathrm{C}$ \\
\hline $\mathrm{C} 7$ & 6 anos & Joinville & $\mathrm{C}$ \\
\hline $\mathrm{C} 8$ & 10 anos & Joinville & $\mathrm{C}$ \\
\hline C 9 & 3 anos e 8 meses & Canoinhas & $\mathrm{C}$ \\
\hline C 10 & 5 anos e 6 meses & Canoinhas & $\mathrm{C}$ \\
\hline C 11 & 12 anos. & Joinville & $\mathrm{B}$ \\
\hline C 12 & 4 anos e 9 meses & Joinville & $\mathrm{B}$ \\
\hline C 13 & 4 anos & Joinville & $\mathrm{E}$ \\
\hline C 14 & 11 anos & Joinville & $\mathrm{C}$ \\
\hline C 15 & 6 anos & Treze Tílias & $\mathrm{C}$ \\
\hline C 16 & 6 anos & Joinville & $\mathrm{C}$ \\
\hline C 17 & 7 anos & Joinville & $\mathrm{C}$ \\
\hline C 18 & 10 anos & Joinville & $\mathrm{C}$ \\
\hline C 19 & 13 anos & Joinville & $\mathrm{C}$ \\
\hline
\end{tabular}

Fonte: Elaborado pelos autores

As experiências foram assim nomeadas: 
a) Noção de Objeto Permanente - Com a criança C3 foi feita a experiência 1A que consistia, na primeira parte, em deixar a criança se interessar por um objeto, depois tomar o objeto dela, tampá-lo com um lenço e ver a reação da criança. A partir dos sete meses de idade, o esperado é que ela saiba que o objeto, apesar de não estar visível, continua ali, o que foi constatado. A criança $\mathrm{C} 3$, logo que o objeto foi tampado, retirou o lenço de cima dele e, tendo encontrado o objeto mostrou grande alegria em fazê-lo, exibindo-o para as pessoas presentes falando sílabas desconexas. A experiência 1B consistia em, à vista da criança, tampar novamente o objeto com um lenço, destampar o objeto e tampá-lo com outro lenço ao lado, caracterizando um deslocamento complexo. O esperado para idades a partir dos 12 meses é que a criança consiga compreender o deslocamento e passe a procurar o objeto sob o segundo lenço, o que foi constatado com a criança C3. Ela mostrava ansiedade em ter o objeto de volta, razão pela qual não ficou passivamente observando o que estava ocorrendo, mas insistia em tentar pegá-lo para si enquanto o deslocamento estava sendo efetuado. Então, assim que o objeto foi deslocado, a criança já o destampou e voltou a brincar com ele.

Observa-se, por conseguinte, que a criança C3 possui as características do final do período Sensório-Motor, como inteligência essencialmente prática e voltada somente para ela e noção de objeto permanente, isto é, a mente está voltada para a resolução de problemas imediatos que a atinjam. Neste caso, ao perceber que o brinquedo lhe foi tirado, a criança C3 imediatamente buscou resolver seu problema procurando o objeto exatamente onde o havia escondido; ela sabia que não havia "sumido", que estava sob o lenço. Pôde-se observar também que a criança C3 está no período de transição entre o Sensório-Motor e o Período Simbólico do PréOperatório, através da utilização de uma linguagem rudimentar e monossilábica para expressar alegria e mostrar que havia encontrado o objeto.

b) Constância da forma - A experiência 2 envolvia constância da forma e consistia em apresentar à criança $\mathrm{C} 4$ uma mamadeira, cuidando porém que, somente que a parte branca (que contém leite) estivesse evidente, sendo que o bico deveria ficar escondido.

Quando C4 realizou esta experiência, ela se mostrou envergonhada diante da câmera que a filmava, porém, quando não estava sendo filmada, ela associou a mamadeira à sua função, que é a de alimentar bebês. A criança, além de identificar a mamadeira, foi capaz de dar um significado ao objeto.

As respostas prováveis de Piaget (1998) são: crianças com até 7-8 meses não conseguem identificar o objeto como sendo uma mamadeira sem que vejam o bico; crianças a partir de 9-10 meses não necessitam visualizar o bico para identificar a mamadeira.

c) Constância da grandeza - O experimento 3 sobre a constância da grandeza consistia em apresentar à criança $\mathrm{C} 4$ duas caixas, de tamanhos diferentes de maneira que não fosse possível visualizar o seu interior. Na caixa maior colocava-se um chocolate, e então se apresentava as caixas à criança $\mathrm{C} 4$, para que ela pudesse abrir somente uma delas. Caso escolhesse a caixa maior, ficava com o doce. Repetindo o procedimento várias vezes, a criança se acostuma a escolher a caixa maior.

d) Noções de Causalidade -Com a criança C12 foi realizada a experiência 4 sobre "Noções de Causalidade", onde se faziam perguntas a respeito de como ou porque ocorriam determinados fenômenos cotidianos. Seguem-se as perguntas e respostas: 
P1) “O almoço está quente; como fazemos para esfriar?"

R) "Bota na geladeira"

P2) "Por que as nuvens se movem no céu?"

R) "Por quê?? 'Prá ficar a noite e claro."

P3) "O que é uma cama?"

R) "Um lugar 'pra' gente dormir, senão a casa fica sem cama e a gente dorme no chão e fica resfriado".

P4) "O que é uma casa?"

R) "Um protetor que guarda as pessoas, todas seguras e com televisão."

P5) “O sol se movimenta? Por que ele se movimenta?"

R) "Movimenta para ir para um outro mundo, 'prá' voltar no mundo, para cada mundo, e voltar no mundo."

P6) "O que faz as ondas do mar se mover?"

$\mathrm{R})$ "O vento. E sabe o que acontece com um vento mais forte? Tão forte que parece um furacão? Forma uma onda gigantesca, que cai na gente e a gente leva um 'caldão'!”

P7) "(fazendo sombra no chão com uma folha sulfite) Por que tem sombra aqui?"

R) "Porque quando é claro faz sombra. Olha aqui (fazendo sombra movimentando o pé no chão), 'tá' vendo a sombra? Então."

Pode-se constatar que a criança C12 está no Período Intuitivo do Pré-Operatório. Ela manipula as palavras mentalmente e é capaz de representar situações, fatos e objetos através delas, já formando frases e colocando-as no tempo gramatical correto. Percebe-se o animismo, característica da fase Simbólica, apenas na P5. A relação causa-efeito é bem presente (embora nem todas as respostas estejam corretas, logicamente). O finalismo, também característico desta fase, é bem claro em algumas respostas, como na P3 e P4. Também se pode perceber a presença de lembranças pessoais junto às respostas, como no caso da resposta à $\mathrm{P} 3$. A ligação de dormir ou permanecer no chão e ficar resfriado deve-se possivelmente a uma recomendação dos pais. A resposta à $\mathrm{P} 4$ apresentava-se de forma lógica até a citação da televisão. Ela ocorreu porque em vista a esta pergunta, a criança começou a elaborar a resposta, olhava para os lados em busca de uma complementação e se deparou com um televisor. Aparece, então, o raciocínio transdutivo. Era possível captar uma ansiedade e uma sensação de importância na criança, que embora estivesse bem à vontade quando respondia às perguntas, se movia ininterruptamente. A criança fez uma associação interessante na P6, relacionando a intensidade do vento com o tamanho da onda e com uma possível experiência pessoal, mostrando uma boa compreensão de causa-efeito misturada a um raciocínio transdutivo: "se o vento causa as ondas, um vento mais forte vai causar uma onda maior, e como me lembro que tomei banho de mar e as ondas me davam um banho, uma onda muito grande vai me dar um banho maior."

e) Conservação de Quantidades - Na conservação de quantidade um objeto ou um grupo de objetos permanecem, ao longo do teste, com quantidade constante, mas com formato, volume ou distribuição alterado. Esperava-se que a compreensão da unicidade ficasse evi- 
dente quando a criança percebesse que, independente da forma ou da disposição de seus elementos, um conjunto unitário mantém sua quantidade constante e, portanto, preserva sua identidade.

f) Conservação de Quantidades Contínuas- A experiência 5 é denominada de transvazamento dos líquidos. Apresentou-se três copos à criança, dois deles altos e de pequena área de seção transversal, outro baixo e de grande área de seção transversal. Os dois primeiros continham o mesmo volume de líquido. Após a verificação dessa condição inicial pela criança, o conteúdo de um dos copos foi transferido, na presença dela, ao copo baixo. Dessa maneira, o copo baixo e um copo alto passaram a conter volumes de líquido idênticos. Perguntou-se à criança qual copo continha mais líquido. As crianças C9 e C10 despejou-se todo o conteúdo de um dos copos na taça. Então perguntou as crianças - "Onde tem mais água? No copo ou na taça?"

A criança C9 respondeu - "No copo porque tá muito cheio, é mais grandão, alto" e a outra, C10 -“ Na taça porque tá mais cheião, mais grande que o copo”.

O experimento 5 chama-se alteração da forma de uma porção de massa. Uma porção de massa de modelar infantil foi apresentada à criança. Com o auxílio de uma faca, dividiu-se a massa em duas partes iguais. Depois, as duas porções foram modeladas em bolas. A criança C23 verificou que as duas bolas eram feitas da mesma quantidade de massa. A seguir, uma das bolas foi esticada na forma de um longo cilindro. Perguntou-se, então, qual dos dois objetos possuía mais massa. A criança prontamente respondeu que o cilíndro tinha mais massa porque era mais comprido.

Perguntaram-se as crianças C9 e C10 - "Onde há mais massa? Na bola ou na salsicha?" A criança C9 respondeu: - "Na salsicha porque é mais esticadão (comprido)" e a C10 - "Na bola porque é muito bola".

g) Conservação de Quantidades Descontínuas - Para a realização do experimento 7, utilizou-se de um copo e de uma tigela, o primeiro alto e de pequena área de seção transversal, o segundo baixo, mas largo. Na presença da criança, feijões foram distribuídos de maneira constante e idêntica entre os dois recipientes, de forma que, durante todo o teste ambos continham a mesma quantidade de feijões. Ao final, perguntou-se em qual dos recipientes havia mais feijões.

Às crianças C9 e C10 foi perguntado:"Onde há mais grãos? No copo ou na taça ?” $d e "(\mathrm{C} 10)$.

Respostas: "No copo porque encheu muito" (C9) e "Na taça, porque é mais gran-

A conservação é uma operação que permite a criança compreender que alterações de forma não causam alteração da quantidade, do peso ou do volume. Crianças em nível préoperatório de desenvolvimento parecem raciocinar apenas sobre estados ou configurações, desprezando as transformações. Por isso, elas observam o resultado final (estado) que é a água no copo e na taça e desprezam a transformação observada, que foi o derramar de água.

$\mathrm{Na}$ fase pré-operacional, a criança é incapaz de descentração, isto é, de centrar sua atenção em dois ou mais aspectos da realidade ao mesmo tempo. Quando focaliza a atenção na altura do copo, ela não consegue ficar atenta à sua largura. 
Os resultados dos experimentos são correspondentes à teoria de Piaget sobre o desenvolvimento humano. As respostas das crianças C9 e C10 são similares as possíveis apresentadas por Piaget, antes do domínio da conservação desenvolvida no período das operações concretas. As crianças são perceptivas apenas a formas ou estados não levando em consideração a quantidade real e as transformações ocasionadas nas experiências, considerando apenas a forma inicial e final.

h) Capacidade de classificação aditiva tátil-cinestésica - Baseado nas teorias de Piaget quanto ao desenvolvimento cognitivo, a experiência 8 foi a respeito da presença de noções operatórias, com a criança C5. Sua faixa etária corresponde ao estágio das operações concretas. É a partir desta fase que, segundo Piaget (1998), a criança começa a ver o mundo com mais realismo, deixa de confundir o real com a fantasia. Como a criança em questão está para seguir ao próximo estágio, operatório formal, pode-se dizer que já possui algumas características desta fase, tal como desenvolver a sua própria identidade, podendo haver neste período, problemas existenciais e dúvidas entre o certo e o errado.

Nos experimentos aplicados, avaliou-se a noção dos conceitos de capacidade de classificação aditiva tátil-cinestésica e de conservação de peso, que Piaget adequou à faixa de oito a nove anos de idade. Teoricamente, a criança avaliada deve apresentar as noções dos conceitos mencionados anteriormente, por estar em uma faixa etária superior à estudada por Piaget.

$\mathrm{Na}$ experiência 8, colocou-se sobre uma mesa, duas bolas grandes e duas pequenas, dois cubos grandes e dois pequenos, dois quadrados grandes e dois pequenos, dois círculos grandes e dois pequenos. A criança C5, vendada, deveria distribuir o material em dois grupos, de acordo com duas possibilidades: tamanho ou forma. Ao começar a experiência, ela decidiu separar os objetos por forma e obteve êxito.

\begin{abstract}
A maioria das crianças mais jovens considera mais difícil classificar de acordo com critérios táteis-cinestésicos, do que com critérios visuais. Piaget verificou, neste tipo de experimento, que é mais fácil distinguir pelo tato objetos os que diferem em tamanho do que pela forma (PIAGET, 1998, p. 25).
\end{abstract}

Conclui-se que, neste experimento, a criança C5 demonstrou características mais avançadas confirmando a teoria de Piaget quanto a faixa etária em que ela se encontra.

i) Conservação de peso - Na experiência 9 relacionada à noção de conservação de peso, iniciou-se com a apresentação dos objetos a serem utilizados: uma balança de dois braços e porções de massa de modelar. Dividiu-se a massa de modelar em duas porções iguais, delas foram feitas duas bolas iguais e colocadas uma em cada braço da balança. A criança C5 notou que havia equilíbrio na balança, portanto, as bolas tinham o mesmo peso. Ao retirá-las da balança, diante da criança, fez-se de uma das bolas um bastão. Em seguida, a criança foi questionada se daquela forma as duas massas teriam o mesmo peso. Obteve-se a resposta de que o bastão seria mais pesado do que a bola porque era maior em comprimento. Após a resposta, colocaram-se as massas na balança e verificou-se que elas continuavam com o mesmo peso.

Ao retirar as massas, fez-se do bastão vários pedaços, picando-o na frente da criança. Novamente questionada sobre o peso, a mesma respondeu que os pedaços eram mais pesados 
que a bola. Mostrou-se para ela que isto não ocorre e que havia equilíbrio entre as duas massas. Em seguida, tomaram-se quatro bolas de massa de modelar colorida. A criança C5 é informada de que, em cada par, as bolas têm o mesmo peso. Diante dela, em cada par de cores, uma das massas é mantida em sua forma e a outra é transformada em triângulo, retângulo, bastão ou é amassada. Dessa forma, perguntou-se a ela em quais dos pares o peso continuava o mesmo, aumentava ou diminuía. No primeiro par, novamente obteve-se a resposta de que uma das massas estava mais pesada que a outra de mesma cor. Ao perceber que nas experiências anteriores, todas tinham o mesmo peso, ela responde que o segundo par mantinha o mesmo peso. Porém, no terceiro par, ela volta a responder que uma das massas estava mais pesada que a outra de mesma cor. Quando se mostrou que continuavam com o mesmo peso, a criança entende que todas as massas realmente tinham o mesmo peso, respondendo então que o último par mantinha o peso inicial e concluindo que independente das alterações de forma das massas, sempre há conservação de peso.

\begin{abstract}
A conservação de peso é uma noção graças a qual a criança compreende que alterações de forma e/ou posição não são acompanhadas de consequentes alterações de peso. A conservação de peso é um conceito alcançado mais tardiamente do que a conservação de quantidade, e que geralmente, de oito anos em diante, as respostas infantis tendem a evidenciar o domínio da conservação de peso. Às vezes, as respostas infantis variam conforme o material usado; provavelmente, isto se deve à familiaridade com o material. (PIAGET, 1998).
\end{abstract}

Observa-se que a criança C5 não possuía tal conhecimento, até ser questionada e presenciar através de experimentos a validade do conceito apresentado.

j) Conservação do volume - Mostrou-se à criança C6 que colocando duas bolas iguais em copos distintos, com o mesmo nível de água, o nível aumentaria igualmente nos dois copos (experiência 10). Transformou-se uma das bolas num formato de bastão. Perguntou-se a ela se ao por a bola num copo e o bastão no outro, aumentaria mais o nível do copo com a bola. A resposta dada por ele foi: "aumentará igual". De acordo com Piaget (1998), para uma criança de 7 anos de idade, a resposta provável seria que a bola ou o bastão aumentaria o nível mais que o outro, ou seja, que não aumentaria de maneira igual. Assim, a resposta dada pela criança não foi de acordo com a teoria de Piaget.

Apresentaram-se a ela dois bastões iguais. Partiu-se um deles em três pedaços iguais, na frente da criança. Colocaram-se, então, os três pedacinhos em um copo e o inteiro em outro. Perguntou-se a ela (C6) porque aumentou o mesmo nível de água em ambos os copos. Primeiramente, ela respondeu que isso havia acontecido porque um dos pedaços tinha sido cortado. Perguntou-se novamente e ela não soube responder. Para Piaget (1998), criança dessa idade ainda não tem o conceito de conservação do volume formado. Logo, a criança comprovou a teoria.

k) Conservação do comprimento - Apresentou-se a criança C6 duas tiras, de papel, iguais e quatro papéis em formato de "V", também iguais. Esses papéis estavam em formato de setas, <-->, <--> (experiência 11) Inverteram-se as extremidades de uma das setas: <--> e $>--<$. Perguntou-se à criança qual deles era maior. A resposta foi: "iguais". A teoria de Piaget diz que, pela idade dela, a resposta provável seria que a seta fechada era menor. 
Mostrou-se um fio de telefone (espiral) e um barbante, cujo comprimento era o mesmo do fio sem estar esticado (experiência 12). Perguntou-se se o fio e o barbante tinham o mesmo tamanho. A resposta foi sim. De acordo com Piaget (1998), nessa faixa etária, ora seria considerado um deles maior, ora as duas seriam consideradas iguais.

Posicionaram-se três lápis paralelamente e foi dito à criança que eram iguais (experiência 13). Colocou-se um deles alguns centímetros para frente. Questionou-se se eles continuavam do mesmo tamanho e a resposta foi sim. Piaget (1998) diz que a criança é capaz, nesta idade de responder corretamente e apresentar justificativas. No entanto, embora a resposta fosse correta, não foi justificada.

A criança C6 está no Pré-operatório, acertando a maioria das respostas, porém, não sabia descrever o motivo das respostas, ou por não ter um conceito formado, ou por estar inibida.

1) Conservação de superfície - A experiência 14 referente à conservação de superfície e consistia apresentar à criança $\mathrm{C} 7$ duas folhas de cartolina com mesmas dimensões representando cada pasto comentando-se que uma vaca comeria um dos pastos, enquanto outra vaca comeria o outro. Depois de apresentar o contexto, começou-se a distribuir sobre os pastos, casas de madeira. Num dos pastos, a partir do centro, e no outro, a partir das extremidades. No final, perguntou-se a criança em qual das duas situações sobraram mais pasto para as vacas. A criança disse que a cartolina com as casas situadas nas extremidades teria mais pasto sobrando, pois as casas estavam mais separadas.

Segundo Piaget (1998), a criança entre 5 e 7 anos acredita que a quantidade de pasto é diferente, bastando mover uma das casas para alterá-la. Só por volta dos 8 anos a criança percebe que as casas estando juntas ou separadas ocupam o mesmo espaço.

m) Conservação de volume espacial - A experiência 15 , referente conservação de volume espacial, consistia em mostrar para a criança C7 uma casa feita de cubos de madeira fazendo com que ela construísse casas que oferecessem aos moradores o mesmo espaço, porém ocupando uma área menor do que a anterior. Quando proposto que ela fizesse a casa, ela construiu uma casa igual à anterior, e disse que seria impossível construir uma casa que oferecesse o mesmo espaço e que ocupasse uma área menor.

Segundo Piaget (1998), entre 5 e 7 anos as crianças acham impossível edificar uma casa mais alta sobre uma base menor. A partir dos 8 ou 9 anos ela já tem essa noção, porém apenas com 11 ou 12 anos ela consegue relacionar matematicamente superfície e volume.

A criança $\mathrm{C} 7$, ao realizar a experiência 14, estava prestando atenção, porém não conseguiu responder corretamente. Simplesmente se sentiu envergonhada após dar a resposta errada, e não deu mais respostas, apenas balançou a cabeça negativamente e sorriu de forma tímida. Na experiência 15, ela teve grande dificuldade em entender o problema proposto, e logo teve sua atenção dirigida para outros fatores, como as demais pessoas da casa ao seu redor, por exemplo. Quando foi solicitada a construção da casa que ocupava uma área menor do que a anterior, pareceu ter pressa na construção desta, e repetiu a estrutura da casa anterior. Ficou claro que ela preferiu dizer que não teria como atingir o objetivo da experiência, a tentar uma nova construção. 
n) Classificação auditiva visual - A experiência 16 realizada com a criança C2 tinha como objetivo verificar a classificação auditiva visual, de acordo com as classificações de Piaget (1998), em conformidade com a idade. Utilizaram-se quadrados grandes e pequenos, azuis, e também círculos grandes e pequenos, vermelhos, deixando que a criança manipulasse os objetos e os descrevesse. A seguir foi solicitado à criança que organizasse o material em classes de acordo com um atributo (cor, tamanho, forma).

De acordo com Piaget (1998), até por volta de oito ou nove anos, a maioria das crianças é capaz de realizar o experimento levando em consideração dois e três atributos simultaneamente.

A criança $\mathrm{C} 2$ descreveu as figuras com facilidade e no princípio separou de forma alternada as figuras que se diferiam, com uma explicação mais precisa começou a separar de acordo como estava sendo pedido, em primeiro por cor, depois por tamanho (grande ou pequeno) e depois por forma. Esse experimento oportunizou a verificação da capacidade de diferenciar formas, cores e tamanhos, além de examinar o desenvolvimento da noção de lógica.

o) Multiplicação Lógica de Classes - A multiplicação lógica de classes (experiência 17) descrita por Piaget (1998) foi realizada com a criança C8. O experimento implica basicamente em analisar a lógica desenvolvida, utilizando um quadrado grande dividido em quatro menores de $4 \mathrm{cmx} 4 \mathrm{~cm}$. Cada um desses quadrados possui figuras semelhantes como: três estrelas iguais não pintadas, três estrelas iguais pintadas, três círculos não pintados e um quadrado em branco, os quadrados devem ser tapados, com exceção do branco.

Foi proposta a identificação dos objetos e a escolha de conjunto de objetos que pertencesse ao quadrado branco, que deveria ser escolhido por meio de comparação. Depois disso perguntou-se à criança por que ela acreditava que aquele conjunto de objetos escolhido pertencia aquele lugar.

Para Piaget (1998) a operação de multiplicação lógica de classes faz com que a criança interaja com duas, três ou mais variáveis que se combinam. A criança C8 obteve um ótimo desempenho respondendo às perguntas com muita rapidez e facilidade, isso significa que está desenvolvido nesse critério para sua idade.

p) Classificação Aditiva Antecipatória -Para o experimento 18, os materiais usados foram: seis triângulos, sendo duas laranjas, dois vermelhos e dois azuis, dos quais um é pequeno e outro é grande. Também foram usados seis círculos e seis quadrados com as mesmas características e alguns envelopes.

O objetivo era verificar a capacidade de comparação e separação segundo a classificação que a criança estabelece, podendo organizar o material de várias formas diferentes. As respostas evidenciam o nível de desenvolvimento da criança.

Nessa fase ocorre o aparecimento da função simbólica ou semiótica. Na classe indução, a criança compreende as relações entre conjunto de objetos e seus subconjuntos e entre os vários subconjuntos. A criança responderia corretamente, em idade entre 5 a 10 anos, aproximadamente, o que é possível que se deva à sofisticação da linguagem. Em geral, a classe lógica é compreendida somente por volta dos 9 ou 10 anos, quando a criança é capaz de 
verificar certas características nos conjuntos e assim consegue responder adequadamente. A classe inclusão é indispensável para compreensão do conceito de números.

Apesar de conseguir cumprir a tarefa de separar os objetos, organizando-os por cores e formas, a criança C11 não compreendeu as relações entre os conjuntos, pois, segundo Piaget (1998), ela não estaria na faixa etária que conseguiria enxergar os conjuntos e subconjuntos. Isto foi reafirmado quando, ao ser solicitada, a criança organizou os objetos de outra maneira e não conseguiu, à primeira tentativa, enxergar outros modos de fazê-lo. Pela organização da criança, foi observado que não há uso da lógica. Há conceitos que já fazem parte do saber da criança, tais como: cores, formas e tamanho. A primeira organização esperada seria a separação por tamanho, porém o que a criança observou primeiramente, foram as cores e em segundo, as formas, deixando o tamanho para análise posterior.

Anterior à tarefa, houve ansiedade por parte da criança e, expectativa por parte do experimentador. Durante a tarefa, a criança colocou-se disposta a realizar o que lhe foi pedido com entusiasmo. O experimento teve longa duração, e houve certa fadiga. Após o término da experiência, a criança organizou os objetos ao seu modo e de forma correta, sentiu-se triunfante e pediu pela repetição do processo.

q) Flexibilidade de Hastes Metálicas -No experimento 19, os materiais utilizados foram: hastes de diversos tamanhos e metais, um suporte de madeira e um peso (no caso, uma chumbada de pesca).

O objetivo era perceber até que ponto a criança isolava as variáveis específicas e conserva outras constantes para verificação de hipóteses específicas. Para resolver a questão, é indispensável usar o raciocínio lógico e observação experimental.

Nesse período, de acordo com Terra (2010), há o egocentrismo intelectual e social caracterizando a fase piagetiana anterior. A criança C13 não consegue estabelecer relações a fim de integrar pontos de vista diferenciados de modo lógico. Não consegue manipular e imaginar questões de forma concreta, apesar de manter um raciocínio coerente. Na fase inicial, a criança compara o efeito de cada fator isoladamente; não os combina e não é capaz de separar as variáveis das constantes. $\mathrm{Na}$ fase final, a criança já consegue separar um fator, deixando os demais invariantes, encontra várias relações para o mesmo resultado, compreende certos conceitos, sem generalizar para os demais casos.

Houve momentos que as questões não eram bem interpretadas e a criança mostrou-se dispersa e desinteressada. Não foi possível analisar corretamente a fase piagetiana, mas percebe-se que ela não conseguiu responder de forma coerente porque duas hastes de mesmo tamanho e mesmo material, porém de grossuras diferentes, têm flexibilidades diferentes. Neste caso, apesar de responder de forma correta qual era a mais flexível, não soube o real motivo porque isso acontecia. Não houve comparação entre as características. Cada fator foi tomado isoladamente, caracterizando o período piagetiano operacional concreto inicial.

A criança C13 mostrou-se impaciente e interessada antes de dar início ao experimento. Durante a atividade, não houve concentração. Mostrou-se dispersa e desinteressada, apesar de concluir a tarefa. Existiram momentos de descontração, mas para o experimentador, foi difícil e complexo fazer com que o sujeito compreendesse e se interessasse pela atividade. 
r) Classificação Multiplicativa - Utilizou-se para o experimento 21 folhas de árvores distintas com tonalidades de verdes e tamanhos diferentes. Foi usada, também uma cartolina dividida em 16 quadrados de $5 \mathrm{~cm}$ X $5 \mathrm{~cm}$ e neles foram coladas quatro espécies de folhas. Cada espécie continha quatro folhas com formatos iguais para cada espécie e cada espécie tendo quatro tons de verde diferentes. Assim todos os 16 quadrados foram colocados na frente dacriança, separados uns dos outros, e ao término foi explicado que ela deveria fazer.

O objetivo do experimento era que a criança conseguisse agrupar as espécies, cada qual com as suas folhas e os diferentes tons formando quatro grupos distintos de folhas.

Como nos experimentos anteriores, segundo Piaget (1998), a criança já tem seu desenvolvimento completo para diferençar formas, tamanho e características que distinguem espécies por fazerem parte de seu cotidiano.

A criança $\mathrm{C} 14$ demonstrou conhecer as espécies apresentadas, mas ainda teve dificuldade de fazer distinção por tamanho ou por detalhes pequenos que elas apresentavam.

s) Seriação simples - Na experiência 22, que trata da seriação simples, a criança era levada a encaixar círculos de tamanhos variados em seus respectivos lugares.

Foi pedido para a criança C16, no início do experimento, que encaixasse em um dos quatro espaços, sete dos círculos que se diferenciavam apenas pelo tamanho. Quando a criança começou a atividade, notou-se que conseguiu desenvolver seu raciocínio para encaixar os círculos nos lugares certos de maneira rápida. Não demorou muito para que ela a terminasse. Apenas em alguns momentos a criança pegava círculos com tamanhos diferentes, em relação ao dispositivo, para fazer a análise, mas nada que não o fizesse terminar a atividade de forma certa e rápida.

De acordo com Piaget (1998) essa é uma atividade lógica em que se faz a seriação de objetos de acordo com o senso espacial. A seriação simples é adquirida pela criança em torno dos 6 anos, sendo que com 8 anos isso já tem que estar enraizado em sua mente. Percebe-se que a criança, a partir das informações colhidas com a experiência, está dentro do período de desenvolvimento proposto de Piaget.

t) Compensação simples - O experimento 23, denominado compensação simples, levava a criança tomar uma solução lógica para um problema físico. Existia um peso que não afundava, e a criança manipulando o meio deveria fazê-lo afundar.

Foi pedido primeiro que a criança C16 analisasse o seguinte fenômeno: pegou-se um pote vazio colocado dentro de um balde cheio de água. Pode-se perceber que o pote flutuava por completo. Depois, foram adicionadas ao porte, algumas pedras e a criança notou que o pote afundou um pouco. A partir daí foi solicitado que C16 afundasse o pote por completo. Rapidamente, sem testes, C16 conseguiu concluir que para afundar o pote era necessário enchê-lo com pedras. Depois de afundado, foram colocadas as mesmas pedras do primeiro pote em um pote maior. A criança conseguiu analisar que o novo pote não afundava completamente, sendo então solicitado a ela que novamente afundasse o pote. Nesta parte a criança teve um pouco de dúvida, mas também nada que não a fizesse terminar a experiência muito rapidamente, enchendo o segundo pote com pedras. 
$\mathrm{Na}$ análise piagetiana, a criança deveria encontrar dificuldades para concluir a experiência. A compensação simples é uma das partes mais importantes no desenvolvimento da criança, principalmente porque é altamente aplicado em suas atividades escolares.

De acordo com a experiência, a criança está no período pré-operacional proposto por Piaget, demonstrando inclusive que está acima de sua fase. Imagina-se que transcorrerá sem problemas sua passagem de fase e seus aprendizados futuros.

u) Seriação Complexa - O experimento 24 é chamado de Seriação Complexa, no qual são entregues à criança 10 palitos de picolé de 5 a 11 centímetros para que ela os ordene do menor para o maior. De acordo com Piaget (1998) a criança na sua faixa etária deverá ordenar os palitos comparando eles em pequenos conjuntos ( 2 a 2 entre outros), não tendo a capacidade de comparar os 3 palitos " $x, y, z$ " ao mesmo tempo, verificando que o palito y é maior que o x, mas ao mesmo tempo é menor que o palito z. A criança $\mathrm{C} 2$ foi capaz de ordenar os palitos fazendo as comparações 2 a 2 como era o esperado para a sua faixa etária.

v) Transitividade - $\mathrm{O}$ experimento 25 consiste em apresentar para a criança, três conjuntos de botões com cores e quantidades diferentes: o conjunto A com 20 botões roxos, o B com 25 botões azuis e o $\mathrm{C}$ com 30 botões verdes. Primeiramente são apresentados os conjuntos A e B, afirmando-se que existem menos botões roxos que azuis. Retiram-se todos os botões da mesa apresentando-se em seguida os conjuntos $\mathrm{B}$ e $\mathrm{C}$, afirmando que agora existem menos botões azuis do que verdes. A seguir, pergunta-se qual é a cor com a maior e a com a menor quantidade de botões.

A criança C15 que entender a transitividade deve ser capaz de classificar os conjuntos usando as duas afirmações feitas anteriormente, falando que o conjunto com mais botões é o C contendo 30 e o com menos é o A contendo apenas 20. A criança C15 foi capaz de responder corretamente as perguntas, desta forma, para este experimento, pode-se afirmar que $\mathrm{C} 15$ entendeu com a transitividade.

No outro experimento realizado (26) foi apresentado um conjunto de vinte peças plásticas pequenas e pretas e vinte e cinco peças similares, mas brancas. Foi dito que havia menos peças pretas do que brancas. Logo em seguida, as peças pretas foram retiradas e trinta peças amarelas foram apresentadas. Dessa vez, foi esclarecido que havia mais peças amarelas do que brancas. Por último, ao mostrar-se todos os três conjuntos de peças, indagou-se qual era o menor conjunto. A criança C24 não só indicou o conjunto preto como o menor, como os classificou por tamanho e deu a razão pelo qual ela respondeu (afirmou que foi dito a ela que o grupo amarelo era maior que o branco e o branco maior que o preto).

w) Compensação Complexa - A experiência 27 sobre compensação complexa tinha por objetivo analisar se a criança $\mathrm{C} 1$ conseguia estabelecer igualdade entre dois sistemas de variáveis. Foram montados e criados 2 (dois) aquários com folhas de "EVA", e 10 (dez) peixes de cartolina. O sistema montado e apresentado para a criança no experimento 27 consistia-se de dois aquários conectados por um tubo de EVA sendo que um aquário possuía 8 (oito) peixes e no outro 2 (dois) peixes.

O aplicador do experimento explicou a situação problema para que a criança identificasse a solução. A situação era: os peixes agem de certa forma fugindo da água fria, do gelo e 
procuram comida. No momento existiam mais peixes em um dos aquários e os aquários estão interligados.

Apresentada a situação foi perguntado o que poderia ser feito para que os aquários tivessem a mesma quantidade de peixes. Em primeiro momento a criança não entendeu a pergunta e respondeu que utilizando instrumentos adequados ela poderia retirar os peixes de um aquário manualmente e colocar no outro, mostrando não entender nem mesmo a situação. $\mathrm{O}$ aplicador repetiu a explicação mais lentamente e refez a pergunta. No segundo momento a criança conseguiu concluir que colocando comida no aquário com menos peixes, resolveria a situação, talvez a criança não tenha entendido a situação dos aquários estarem interligados, e na segunda explicação por perceber estar errada a resposta, tenha procurado alternativas.

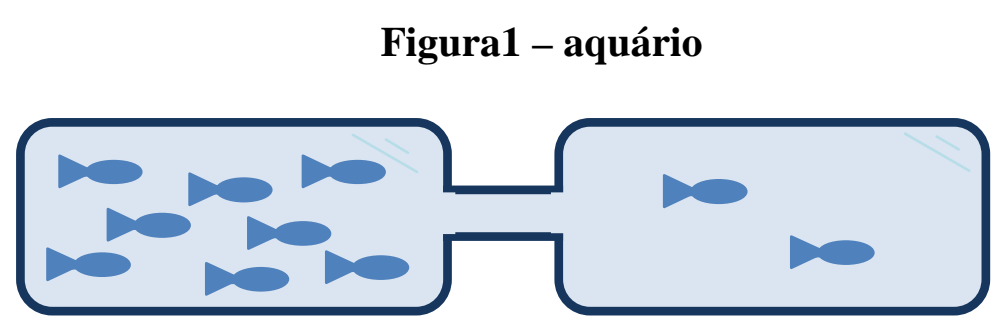

Fonte: Elaborado pelos autores

As conclusões de Piaget são: de 7 a 9 anos a criança encontra dificuldade em analisar a compensação complexa que envolve várias variáveis, e utiliza-se de recursos mais fáceis; de 9 a 11 anos ela entende e conclui que movendo as variáveis ocorre a compensação. Nesse experimento dever-se-ia equilibrar quantidade de peixes entre os dois aquários, isso é, relacionar que colocando água fria onde tinha mais peixes, esses passariam para o outro aquário, ou colocando comida no aquário onde tinha menos peixes, esses passariam para o aquário com a comida.

x) Operação lógica de probabilidade - A experiência 28, operação lógica de probabilidade, tinha por objetivo analisar se a criança $\mathrm{C} 1$ conseguia formar probabilidade entre as várias variáveis. Foram colocadas 15 (quinze) bolinhas de cor rosa, 10 (dez) bolinhas de cor azul, 8 (oito) bolinha de cor branca, 5 (cinco) de cor prata e uma caixa fechada e opaca. Foi apresentada a seguinte situação para a criança: todas as bolinhas seriam colocadas na caixa não sedo possível ver o que poderia ocorrer lá dentro. Em seguida, seria tirada uma bolinha.

Figura 2- Caixa com bolinhas

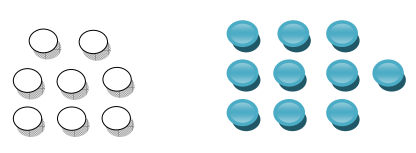

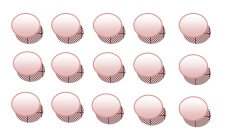

Fonte: Elaborado pelos autores
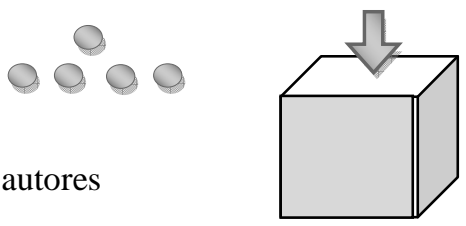
Foram contadas durante a colocação das bolinhas, uma a uma, para que a criança percebe-se a quantidade de cada uma das cores (rosa, azul, branca, prata) e em seguida o aplicador perguntou qual bolinha possivelmente seria retirada. A resposta da criança $\mathrm{C} 1$ foi de conclusão rápida. Ela concluiu que a bolinha de cor azul era a que se tinha em maior quantidade, então seria a que possivelmente seria extraída.

As conclusões de Piaget são: de 7 a 9 anos a criança encontraria dificuldade em estabelecer relações de probabilidade, o que levaria a criança a relacionar a sua preferência de cor com a que seria extraída ao invés de usar a probabilidade; e de 9 a 11 anos ela analisaria a quantidade de bolinhas colocada e perceberia as relações de probabilidade; e de 11 anos em diante conseguiria estabelecer até mesmo a fração numérica da probabilidade, como por exemplo $3 / 9$ ou $2 / 6$ etc.

A criança $\mathrm{C} 1$ demonstrou-se tímida diante da filmagem e apenas no momento de responder que se apresentou dinâmica e espontânea. Independentemente da dificuldade que vivenciou no primeiro experimento ela resolveu corretamente os dois problemas apresentados.

Segundo Piaget (1998) a criança C1 deveria estar na fase operacional concreta, no início (7 a 9 anos) ou no final (9 a 11 anos) desta fase. Analisando as experiências conclui-se que está exatamente no meio da fase. Se a criança $\mathrm{C} 1$ tivesse interpretado rapidamente a "compensação complexa" ela estaria no final da fase, o que não aconteceu. Caso a criança tivesse estabelecido uma relação mais consistente, já envolvendo números na "operação lógica de probabilidade", ela estaria no final da fase, o que também não aconteceu.

Em uma rápida avaliação, percebe-se que as teorias de Piaget se encaixam bem na criança $\mathrm{C} 1$. Como a criança possui 9 anos, ela poderia tanto estar na fase inicial como na final da operacional concreta. Percebeu-se, também, que no primeiro experimento ela teve dificuldade, já no segundo ela teve mais facilidade, sendo que deveria ter um desempenho igual para definir melhor entre inicial e final da fase.

y) Pensamento proporcional - Experiência Pictórica: Foram pesquisadas as crianças C17 e C18. As crianças, segundo Piaget, pertencem ao período operatório concreto, nesse período as crianças deveriam já possuir o raciocino concreto sobre conservação de números, substancias, volume e peso, ou seja, possuir um raciocínio coerente.

Na experiência intitulada Experiência Pictórica (29) foi apresentado às crianças C17 e C18 o seguinte problema: duas arvores de mesmo tamanho são mostradas em forma de figura, onde a árvore A cresceu $80 \mathrm{~cm}$ em 1 ano e a árvore B cresceu $200 \mathrm{~cm}$ em 2 anos.

- A seguir foram feitos os seguintes questionamentos:

- As duas árvores cresceram na mesma proporção?

- A árvore A cresceu mais rapidamente que a arvore B?

- A árvore B cresceu mais rapidamente que a arvore A?

- Como era de esperar, as crianças responderam corretamente os questionamentos.

z) Combinações de ideias - Na experiência de Combinação de Ideias (31), foi apresentado à criança C19, o seguinte problema: 
1. Existem 5 casas, cada qual de uma cor diferente e habitada por um homem de nacionalidade diferente, com animais de estimação também diferentes, que gosta de frutas diferentes e consome diferentes bebidas.

2. O inglês mora na casa vermelha.

3. O espanhol tem um cachorro.

4. Na casa verde bebe-se café.

5. O ucraniano bebe chá.

6. A casa verde fica imediatamente à sua direita, com relação à casa de cor marfim.

7. O homem que come morango é dono dos caramujos.

8. Come-se maçã na casa amarela.

9. Na casa do meio bebe-se leite.

10. O norueguês mora na primeira casa à esquerda.

11. O homem que come acerola mora na casa ao lado do homem da raposa.

12. Come-se maçã na casa ao lado daquela em que se guarda o cavalo.

13. Quem come banana, bebe suco de laranja.

14. O japonês come Manga.

15. O norueguês mora ao lado da casa azul.

16. Toma-se café na casa ao lado daquela em que existe o cachorro.

A criança deve responder:

- Quem toma água?

- Quem é o dono da zebra?

Para responder esse questionamento a criança deve relacionar o que o problema fornece, e assim pode-se perceber a capacidade de combinações que a criança pode fazer.

A criança C19 atende as expectativas de Piaget, sendo que a mesma tem 13 anos e faz as combinações com coerência.

A criança desenvolveu o seguinte quadro:

Quadro 2- Quadro das respostas desenvolvido pela criança C19

\begin{tabular}{|c|c|c|c|c|c|}
\hline Cor da casa & Amarela & Azul & Vermelha & Marfim & Verde \\
\hline Nacionalidade & Norueguês & Ucraniano & Inglês & Espanhol & Japonês \\
\hline Bebida & Água & Chá & Leite & $\begin{array}{c}\text { Suco de } \\
\text { laranja }\end{array}$ & Café \\
\hline Fruta & Maçã & Acerola & Morango & Banana & Manga \\
\hline Animal & Raposa & Cavalo & Caramujo & Cachorro & Zebra \\
\hline
\end{tabular}


Fonte: Elaborado pelos autores

Com o quadro desenvolvido, a criança conseguiu responder corretamente os questionamentos.

\section{CONCLUSÃO}

Os 31 experimentos apresentados neste artigo são semelhantes aos que Piaget realizou com crianças e adolescentes quando propôs as 4 etapas do desenvolvimento cognitivo. A maioria das experiências realizadas comprova, que apesar de tantas evoluções tecnológicas e avanços científicos, as crianças da atualidade desempenharam-se de maneira compatível com os experimentos realizados por Piaget.

Os acadêmicos do curso de Licenciatura em Física, que aplicaram os experimentos, consideram que é possível aproveitar esse método nas disciplinas de ensino fundamental e médio, não para medir a capacidade dos educandos em resolver determinados problemas propostos pelo professor ou assimilar o conteúdo, mas verificar as dificuldades de compreensão do aluno com o decorrer da aula. Assim, cabe ao professor identificar os problemas e procurar uma forma de minimizá-los, analisando tanto sua prática pedagógica como outros fatores intervenientes no processo educacional.

No caso específico da Física, de acordo com os acadêmicos, as experiências realizadas podem ser relacionadas com inúmeras atividades do dia-a-dia, pois a Física está presente no cotidiano das pessoas mesmo que elas conscientemente não associem determinados fenômenos aos conceitos físicos.

Neste sentido, pode-se dizer, por exemplo, que os experimentos 8 e 9, assim como o referente à conservação de peso estão associados à Física na solução de problemas e no entendimento de fenômenos como queda de objetos, ou o lançamento de objetos sobre um plano, pois mesmo que a forma se altere por atrito ou por outra força atuante, se não houver perda de massa, não haverá alteração no peso.

Em relação à conservação do volume, podem-se estudar outros fenômenos físicos como: a vazão, a dilatação, entre outros.

Além disso, a Física utiliza-se da lógica e das combinações, logo a multiplicação lógica de classe é muito importante para desenvolver esses conceitos. As formas geométricas podem ser associadas, também, ao cálculo de áreas tão empregado na Física.

No caso das crianças apresentarem algumas dificuldades, como no caso da $\mathrm{C} 1$ que não conseguiu analisar as variáveis no aquário, faz-se supor que se ela estudasse Física poderia não executar corretamente a manipulação de variáveis nas diversas equações dos fenômenos físicos. Em geral, esse tipo de dificuldade é percebido no Ensino Médio.

Já os experimentos sobre noções de peso, material e medida são fundamentais para cálculos físicos, tais como elasticidade do material, durabilidade, entre outros.

A seriação complexa pode ser relacionada com a Física para que os estudantes entendam a variação de volumes, assim estabelecendo comparações com conteúdos como a densidade, que está diretamente conectado às ideias de hidrostática e termodinâmica. As combina- 
ções de objetos podem estar relacionadas a possíveis combinações de variáveis, importante artifício matemático usado na Física.

A relevância de experiências, como estas, deriva da importância da internalização de diversos conceitos, entre eles o conceito de número devido a necessidade desse domínio para o aprendizado de conceitos sofisticados das ciências, em especial das que dependem, em sua base, da quantificação e das relações matemáticas, como Física e Química.

Além do mencionado, as experiências, podem estabelecer associações com a cinemática, na relação explícita de velocidade, espaço e tempo. Elas podem ser trabalhadas de forma simples, sem qualquer cálculo, ou serem obtidas através da equação: espaço dividido pelo tempo, por exemplo. Ao mesmo tempo podem ser trabalhadas de forma mais aprofundada, mostrando aceleração, deslocamento escalar, assim como a velocidade média.

Do mesmo modo é possível relacionar alguns experimentos com conceito de Força. As bolinhas ao serem perfuradas pelo espeto sofrem uma força (que é contrário ao movimento - o atrito da bolinha com o espeto). A força exercida para furar a bolinha terá que ser maior que $o$ a força de atrito, assim rompendo a tensão da bolinha para que o espeto a atravesse.

É importante ainda, considerar que num projeto como este, muitas crianças podem sentir-se ansiosas pelo simples fato de estarem sendo filmadas. O que eventualmente pode influenciar suas respostas. Os motivos são variáveis: por medo de errar, acabam respondendo as perguntas não por suas próprias conclusões. Podem ainda, pensar que o pesquisador tem outra opinião e tentar adivinhar qual seria a resposta que ele espera, entre outras situações. No entanto, a maioria das crianças pesquisadas manteve-se calma, não demonstrando estar sendo influenciada pelo vídeo ou pelo pesquisador, o que oportuniza uma margem maior de precisão na avaliação dos resultados dos experimentos. A criança C6 reflete grande parte dos sentimentos apresentados pelos sujeitos pesquisados, demonstrando-se curiosa, ansiosa, alegre e em alguns momentos envergonhada.

Além disso, pode ocorrer que o pesquisador crie expectativas em relação às respostas das crianças gerando, com isso, ansiedade. Por outro lado, para quem realmente um dia dará aulas, essa vivência, irá ser enfrentada e é necessário que, desde a graduação, se aprenda que coisas elementares para os professores, podem não ser tão elementares assim para uma criança que não obteve um bom desempenho.

Para finalizar, em virtude dos relatos desenvolvidos pode-se dizer que apesar de existir um grande avanço tecnológico nos últimos tempos, a teoria de Piaget continua sendo atual e enquanto algumas crianças apresentam desenvolvimento extremamente rápido, outras, têm um desenvolvimento tardio.

\section{REFERÊNCIAS}

PIAGET, J. Seis estudos de psicologia. São Paulo: Editora Forense, 1998.

PULASKI, M. A. S. Piaget: perfil biográfico. In: . Compreendendo Piaget: uma introdução ao desenvolvimento cognitivo da criança. São Paulo:: Zahan Editora, 1980

SANTANA, Juvenal. Psicologia do Desenvolvimento. Disponível em: $<$ http://www.brasilescola.com/psicologia/psicologia-do-desenvolvimento.htm>. Acesso em 25 abr. 2010. 
Análise piagetiana do desenvolvimento cognitivo: experiências com crianças do Ensino Fundamental

SILVA, T. T. da. Em resposta a um pedagogo 'epistemologicamente correto'. Educação e Realidade, Porto Alegre, v. 19, n. 2, p. 9-17, jul/dez., 1994. 